Revista Mídia e Cotidiano

Artigo Seção Livre

Volume 11, Número 1, abril de 2017

Submetido em: 10/04/2017

Aprovado em: 30/04/2017

\title{
TERRORISMO MIDIÁTICO: disseminação do medo em programa televisivo francês
}

\section{NEWSWHORTHY TERRORISM EVENT: the spread of fear in French TV}

\author{
Janaina Cardoso da SILVA ${ }^{1}$; Christina Ferraz MUSSE ${ }^{2}$
}

Resumo: $\mathrm{O}$ artigo apresenta a análise de um programa de televisão exibido pelo canal francês France 2 que revive, um ano depois, detalhes dos ataques terroristas que marcaram o dia 13 novembro de 2015, em Paris, quando 130 pessoas foram mortas e outras 350 se feriram enquanto se divertiam no que seria uma noite habitual de sexta-feira. O objetivo é discutir a opção da produção pela utilização de elementos estéticos típicos de fillmes de ação e suspense. A construção de uma narrativa que, além de chocar imageticamente, revela erros e despreparo das instituições no socorro às vítimas, na atuação das forças de elite e na segurança do país. O artigo pretende argumentar que o papel da veiculação midiática da verdade com linguagem sensacionalista contribui para disseminação do medo, da insegurança e da xenofobia coletivos na sociedade contemporânea.

Palavras-chave: Risco; Medo; Sensacionalismo; Terrorismo; França.

Abstract: This case study assesses a TV report broadcasted by the France 2 Channel, which revives, one year later, the details of the terrorist attacks which marked the 13th of November, 2015, in Paris. 130 people were murdered and 350 more got injured while enjoying a regular Friday night. The objective is to discuss the producers' choice to use aesthetic elements which are commonly found in action and thriller movies. The paper examines the construction of the narrative and reveals mistakes made by the institutions when they had to provide immediate aid to the victims, as well as the role that they country's elite forces played in its security. The article also analyzes whether the broadcasting of trues facts was combined to a tabloid style language, which contributed to fomenting mass fear, and a sense of insecurity and xenophobia within contemporary society.

Keywords: Risk; Fear; Sensationalism; Terrorism; France.

1 Jornalista com MBA em marketing; mestranda em comunicação pela UFJF na linha cultura, narrativas e produção de sentido. Integrante do grupo de pesquisa Comunicação Cidade e Memória. E-mail: janacard36@hotmail.com.

Jornalista, professora, doutora em comunicação pela UFRJ. Docente integrante do programa de pós-graduação em comunicação da UFJF; líder do grupo de pesquisa Comunicação, Cidade e Memória. Email: cferrazmusse@gmail.com. 
Introdução

A noite de 13 de novembro de 2015 marcou a história da França. Ataques terroristas coordenados em Paris, mataram 130 pessoas e deixaram mais de 350 feridas, várias, em estado grave. Cinco restaurantes, uma casa de shows - Bataclan - e as proximidades do Stade de France que recebia um jogo amistoso entre a seleção da França e a seleção da Alemanha, foram atacados simultaneamente e chocaram o mundo.

Um ano após os ataques, o canal de TV France 2 exibiu no dia 13 de novembro de 2016, um programa jornalístico ${ }^{3}$, com duas horas de duração, narrando os detalhes da tragédia, rememorando a dor, o sofrimento e expondo uma série de erros que incluem falhas no serviço nacional de informações do governo, despreparo da polícia, atrasos no início da intervenção das forças especiais de segurança, rixas entre esquadrões de elite, protocolos rígidos que ocasionaram inadequação nos procedimentos de socorro, além de comunicação equivocada às famílias das vítimas. O nome do programa: "Célula de crise 13 de novembro, quando a França vacila",4, já revela a opção por uma metanarrativa específica: a insegurança de uma sociedade entregue ao azar. "O que seria uma partida de futebol, um show ou uma ida a um bar, foge do esperado e surpreende as pessoas ao dar lugar a cenas de violência, desespero e morte." (SOUZA, 2016). Após duas horas de programa, duração de um longa metragem, a mensagem é clara: ninguém mais está seguro, seja em Paris, seja em qualquer lugar do mundo. As liberdades estão em jogo. Viver o cotidiano passa a ser arriscado. "A proteção de todos depende cada vez menos de políticas assistenciais centralizadas e cada vez mais de condições suficientes para tornar cada um apto a assumir seus próprios riscos". (NEVES, 2014) em um mundo pleno de ameaças globais. "Quem - como Colombo - saiu em busca de novas terras e continentes por descobrir, assumiu riscos. Estes eram, porém, riscos pessoais, e não situações de ameaça global" (BECK, 2010).

\footnotetext{
3 "Célula de crise 13 de novembro, quando a França vacila". No Brasil, o programa foi exibido pelo canal internacional TV5 Monde no dia 14/11/2016. O programa é uma produção Brainworks com a participação da France Televisions. <https://www.youtube.com/watch?v=Wt8Hk3-L7OI>. Acesso em 19 de novembro de 2016.

4 Tradução nossa.
} 
A sociedade cosmopolita globalizada e a evolução tecnológica que possibilitou a comunicação instantânea, a facilidade de locomoção ao redor do planeta e a intensa interculturalidade, transformou inimigos em riscos e perigos, como explica Giddens (1999). A sociedade pós-moderna em sua visão "não é firme nem segura, mas repleta de ansiedade, bem como marcada por profundas divisões" (GIDDENS, 1999). Ao mesmo tempo que interliga o mundo em intrincadas redes de relações econômicas, tecnológicas e culturais, a globalização em sua complexidade paradoxal, na opinião de Giddens (1999), é também responsável pelo fortalecimento das identidades culturais. "Nacionalismos locais brotam como uma resposta às tendências globalizantes, à medida que o domínio dos estados nacionais mais antigos se enfraquece" (GIDDENS, 1999). Giddens (1999) assinala ainda outro grande e intrigado dilema entre dependência e autonomia, entre a perspectiva cosmopolita e o fundamentalismo argumentando que, quando grupos religiosos extremistas atacam cidadãos desprevenidos para reivindicar as linhas dos textos de suas escrituras estão apenas respondendo às influências globalizantes.

Fundamentalismo não é o mesmo que fanatismo ou que autoritarismo. Os fundamentalistas reclamam um retorno aos textos ou escrituras básicas, a serem lidos de maneira literal, e propõe que as doutrinas derivadas de tal leitura sejam aplicadas à vida social, econômica, política (...). Fundamentalismo é tradição sitiada - por referência à verdade ritual - num mundo globalizante que exige razões (GIDDENS, 1999, p.58).

$\mathrm{Na}$ opinião do autor, não se trata apenas daquilo em que as pessoas acreditam, mas da forma como acreditam e justificam sua crença. Enfatiza ainda que o fenômeno não é intrínseco apenas à religião, mas à política, à etnia e ao nacionalismo. "É uma recusa ao diálogo, em um mundo cujo ritmo e continuidade dependem dele" (GIDDENS, 1999). Sua teoria afirma ser o fundamentalismo "filho da globalização" e originário no mais profundo mundo das tradições. $\mathrm{O}$ autor explica que no mundo globalizado e tecnologicamente sofisticado, onde pessoas distantes passam a ter acesso - via imagens e informações transmitidas ao vivo ao redor do planeta - a estilos de vida e pensamentos diferentes, as reações inevitavelmente serão diversas. "Os cosmopolitas acolhem essa complexidade cultural com satisfação e a abraçam. Os fundamentalistas a vêem como perturbadora e perigosa [...]. Eles se refugiam numa tradição renovada e purificada - e, com muita frequência, na violência" (GIDDENS, 1999). 
Zigmunt Bauman (2002) em sua obra Modernidade líquida, define a convivência com o "diferente" como uma arte. "Quanto mais eficaz a tendência à homogeneidade e o esforço para eliminar a diferença, tanto mais difícil sentir-se à vontade em presença de estranhos, tanto mais ameaçadora a diferença e tanto mais intensa a ansiedade que ela gera" (BAUMAN, 2000). Da insegurança e do medo gerado pelos "estranhos no portão" nasce a xenofobia como um porto seguro abrigado pela identidade comum e não mais por interesses partilhados. A alteridade está em crise. Neves (2014) em sua tese de doutorado, ${ }^{5}$ cita Baudrillard na abordagem do tema segurança, controle e prevenção. "São conhecidos os extremos perigosos, que podem levar à profilaxia em todos os domínios - social, médico, econômico, político - em nome da mais alta segurança, pode-se instalar um terror endêmico" (BAUDRILLARD, 1990, apud NEVES, 2014). Há uma nova ordem de laços sociais frágeis no mundo segundo Bauman (2000), que teme a invasão de "corpos estranhos" e pulsa de uma necessidade de purificação para se proteger, estruturando a origem de novas políticas de separação étnicas e barreiras contra a chegada de estrangeiros.

Em artigo publicado para o Intercom 2016, Fabíola Souza (2016) relata o testemunho ${ }^{6}$ de Gabriel Gaspar - jornalista brasileiro residente em Paris - em que o entrevistado fala sobre o medo de pessoas com ascendência árabe ou possuidores do tipo físico árabe de saírem às ruas logo após os ataques de 13 de novembro. "Os muçulmanos que vivem em Paris se mostram apreensivos em relação ao preconceito e às retaliações dos franceses, se configurando também como vítimas do atentado" (SOUZA, 2016). O risco aí assume novas vertentes. Todos passam a temer a todos. Para Ulrich Beck (2010) em Sociedade de Risco, a vida cotidiana é fortemente afetada pela disseminação das ameaças no mundo moderno.

Em situações de ameaça, consequentemente, as coisas da vida cotidiana convertem-se, praticamente da noite para o dia em cavalo de Tróia, do qual se precipitam perigos, e com eles, os especialistas do risco, para anunciar, em

\footnotetext{
5 NEVES, Teresa Costa. Comédias de uma vida arriscada: risco e riso na crônica contemporânea brasileira. 2014. 218 f. Tese (Doutorado em Letras) - Faculdade de Letras, Universidade Federal de Juiz de Fora, Juiz de Fora. 2014.

6 Relato realizado em matéria exibida pelo programa da TV Globo, Fantástico em 15/11/2015.
} 
meio a pelejas mútuas, do que é que se deve ter medo e do que não" (BECK, 2010, p.64).

Quando um programa jornalístico de televisão decide homenagear e rememorar a data de uma tragédia terrorista exibindo o resultado de uma extensa investigação jornalística que desvela, além da arquitetura da maldade, erros graves no processo de segurança de um país, atacado por uma rede terrorista internacional que se afirma muçulmana radical, estabelece-se e consolida-se dessa forma um "outro" com altos níveis de perigo. Kleber Mendonça (2002) aponta estudos realizados em vários países do mundo que discutem a relação entre o aumento da sensação de insegurança e a violência veiculada diariamente na mídia para justificar que "o medo social não se baseia em fatos estatísticos concretos, mas numa ansiedade produzida simbolicamente a partir de informações recebidas" (MENDONÇA, 2002).

Políticas de separação étnicas citadas por Bauman (2000) demostram que esforços não faltam para manter o "diferente" à distância, como a sistemática fortificação e a burocratização de fronteiras, que só permitem o trânsito de pessoas que possuem a mesma identidade. Essas são situações que revelam para o autor a fragilidade ou fluidez dos laços sociais. Para Bauman, a exclusão de pessoas tachadas como estrangeiras pela nossa incapacidade de lidar e conviver com o "outro" é um indicativo de patologia social do espaço público e da política. Ainda segundo ele, os governos em sua impotência não conseguem atacar as raízes da insegurança e da ansiedade dos cidadãos e se refugiam no fechamento de seus territórios e na recusa ao diálogo com o "outro" (BAUMAN, 2000). A amplificação midiática sensacionalista de atos terroristas praticados, em sua maioria, por franceses muçulmanos descendentes de árabes, como no caso do 13 de novembro de 2015, reforça ainda mais a xenofobia e o medo deste "diferente", mesmo tendo ele nascido em território francês.

\section{Sensacionalismo terrorista, narrativa de choque: Metodologia}

O estilo sensacionalista de informação surgiu em meados do século XIX na Europa, direcionado a uma população carente financeiramente, mas ávida por informação e se espalhou rapidamente pelo mundo, como esclarece Mendonça (2002). Com a evolução tecnológica, a imprensa de larga escala necessitava de leitores suficientes que garantissem 
seu sustento publicitário e uma posição dianteira frente aos concorrentes. Mesclando em sua narrativa realismo e romance, contudo, com personagens reais, as notícias sensacionais sempre envolveram tragédias cotidianas. "Esse tipo de jornalismo pode ser caracterizado como de sensações porque ele estabelece um diálogo com os mitos e com uma literatura que subsiste há séculos [...]. Fala de crimes, mortes, suspeitas, tudo que foge à ordem" (MATHEUS, 2011). Matheus (2011) o define como um jornalismo espetacular e desproporcional que pode ser realizado estrategicamente até mesmo por veículos categorizados como sérios.

Utilizando-se dos conceitos e métodos da análise de conteúdo - conjunto de técnicas de análise de comunicações - proposta por Laurence Bardin (2016), pretende-se analisar no programa exibido pelo canal francês France2, as mensagens por trás das evidências, desconfiar dos pressupostos, transcender as aparências, propondo uma ruptura crítica com a leitura "simples do real" editado e exibido na narrativa televisiva apresentada. Tal esforço analítico tem o objetivo de revelar o significado implícito na escolha da estética sensacionalista, linguagem e edição escolhidas pelo objeto analisado. Bardin (2016) afirma que "qualquer comunicação, isto é, veículo de significados de um emissor para um receptor, controlado ou não por este, deveria ser escrito, decifrado pelas técnicas de análise de conteúdo" (BARDIN, 2016). A natureza do código e o suporte para a análise serão a linguística, oral e de comunicação de massa. Optou-se por uma análise descritiva dos "significados" contidos no conteúdo (imagens, reconstituições, entrevistas, artes gráficas, animações, gravações reais, efeitos sonoros, trechos de entrevistas, off, falas do apresentador) exibido pelo programa com a finalidade de interpretar as causas e consequências das escolhas de produção e edição deste material correlacionando-os com a fundamentação teórica apresentada no artigo. A intenção é realizar uma inferência no conteúdo da mensagem transmitida através de descrição e interpretação.

\section{Análise do programa: espetacularização do medo}

O programa exibido pelo canal France 2, cuja programação inclui telejornalismo, documentários e entretenimento de qualidade, se constitui em uma mistura de jornalismo investigativo, analítico e, nesta produção, sensacionalista. Já os três primeiros minutos e 
dezenove segundos que compõem a abertura do programa não deixam dúvidas: com trilha sonora de suspense, imagens reais e simuladas da tragédia vão sendo intercaladas em cortes rápidos, com trechos da fala do presidente da França, François Holande, transmitida ao vivo em rede nacional, ainda na noite dos atentados. Holande anuncia entre sons de tiros e imagens caóticas este "momento tão difícil" à população francesa. Depoimentos que serão assistidos na íntegra durante toda a produção televisiva são exibidos em trechos curtos, intercalados com imagens reais, sons de tiros, luzes, sirenes de ambulâncias, áudios de comunicações do rádio da polícia no momento dos atentados. Imagens de correria e vítimas sangrentas sendo socorridas tomam conta da tela também em cortes rápidos que conferem ritmo alucinante à edição, típico de filmes policiais de ação. Em meio ao caos da primeira edição de imagens, o apresentador David Pujadas assume a condução do programa. Na bancada do estúdio de jornalismo do canal France2, Pujadas informa que o material que os telespectadores vão assistir não foi autorizado pelo Ministério do Interior Francês, enfatizando que vários dos participantes que aceitaram dar seu depoimento o fizeram sob risco. $\mathrm{O}$ apresentador define o conteúdo que será exibido como um documento que vai questionar se a França, mesmo em estado de vigilância máxima desde os atentados que mataram 17 pessoas e feriram outras 18 - no jornal Charlie Hebdo, em Montrouge e no estabelecimento Hyper Cacher ${ }^{7}$ - em janeiro do mesmo ano de 2015, estava mesmo preparada para se proteger. A dúvida sobre a eficácia dos procedimentos de segurança do país é lançada então em primeiro plano no colo do telespectador. Um claro argumento que tende a prender a atenção daqueles que talvez nem tivessem a intenção de assistir o programa até o final. A estratégia de retenção da audiência fica clara já nos trechos das entrevistas editados ainda para a abertura do programa que privilegiam momentos em que as testemunhas já anunciam o despreparo da polícia francesa para enfrentar este tipo situação e falhas na atuação das forças de ordem nacionais. O bombardeio de informações que desorientou policiais, o choque do serviço de investigação antiterrorista ao constatar o acontecido, além de problemas no repasse de informações ao comando de atuação dos esquadrões de elite também são enfatizados. O programa, já nos primeiros minutos, revela sua intenção implícita: utilizar-

$7 \quad$ Os atentados aconteceram em Paris, entre os dias 07 e 09 de janeiro de 2015. 
se do medo, da dúvida, da sensação de insegurança para aguçar a curiosidade do telespectador, refém incondicional de uma sociedade de risco iminente. Uma entrevista com o juiz antiterrorista Marc Trèvidic afirma que o líder dos ataques, Abdelhamid Abaaoud tinha obsessão por atacar a França. Atrasos e dificuldades no socorro às vítimas, o medo dos cidadãos, a falta de viaturas disponíveis da polícia para acessar os locais atacados e o relato de um refém, sobrevivente da casa de shows Bataclan, Stéphane T., destacando, na edição de sua fala, o trecho em que afirma que pensou verdadeiramente que todos os reféns iam morrer, revelam um resumo impactante do conteúdo, além da estética na construção narrativa que virá a seguir. Finalizando a abertura, Pujadas afirma que a produção pretende revelar "a confusão, a coragem, os erros e também os golpes de sorte vividos neste terrível dia". 8

O programa com duração de filme documentário, duas horas, e roteiro similar a filmes policiais de ação recria, através de representações simuladas, várias cenas da noite dos ataques de acordo com os resultados das investigações policiais. A narrativa é cronológica e didática. Há utilização de arte gráfica como recurso a fim de mostrar a movimentação dos terroristas pelo mapa de Paris, ligando cada grupo de extremistas ao local onde cometeu os ataques. Cria-se assim, um clímax para cada ataque seguindo preceitos das narrativas clássicas em sua produção de sentido. As cenas simuladas são escuras, com jogos de luz e sombra, movimentos de câmera lenta intercalados com uma câmera que acompanha os policiais em ação. Há closes em armas, lanternas com feixes luz direcionados, escudos, coletes, capacetes. Sons de sirenes, luzes de viaturas policiais são intermitentes. Close nos carros, armas, celulares e partes dos corpos dos terroristas também integram o conjunto cênico das imagens simuladas. Nota-se aí uma linguagem próxima às séries policiais televisivas, repletas de ação, suspense em sua tentativa de representação do real. Há nesta escolha estética a intenção de afetar o telespectador, trazendo-o para dentro do cenário dos ataques, reforçando assim seu sentimento de vítima, diminuindo dessa maneira sua potência de agir. Além das simulações das cenas vividas em cada local dos ataques, a produção criou animações em 3D detalhando a ação dos terroristas em cada endereço. As animações são cobertas pelos relatos em off de cada

$8 \quad$ Tradução nossa. 
acontecimento. Nelas, os terroristas são representados por bonecos na cor negra e as vítimas são sempre bonecos brancos. O obscuro versus o puro. Essa imagem ideologicamente implícita na escolha das cores já denota imenso racismo. Há uma costura cronológica de tempo com a apresentação da hora e minuto de cada ataque. O saldo de mortos e feridos em cada local é também enfatizado após a descrição da ação em cada restaurante, bar, no estádio de futebol ou na casa de shows. Esse saldo apresentado como estatística tem por efeito chocar. As vítimas viram números, impotentes frente à realidade violenta que as encontraram nesta trágica noite de 13 de novembro. Mais uma vez a sensação de insegurança e impotência frente ao destino desastroso está enfatizada. Durante todo o programa, intercalam-se às animações, simulações e arte gráfica com o movimento dos terroristas pela cidade, imagens reais gravadas por celulares ou de câmeras de segurança, áudios reais do rádio de comunicação da polícia, depoimentos de sobreviventes, voluntários, testemunhas, socorristas e policiais que atuaram na noite dos ataques, conferindo e certificando a realidade dos fatos representados e apresentados. Uma realidade cruel exposta como uma veia aberta sem condições de sutura.

Segundo Letícia Matheus (2011), “o medo é um importante desencadeador e também encadeador de histórias que proporcionam uma experiência simbólica da vida urbana" (MATHEUS, 2011). Citando o historiador francês, Jean Delumeau, em seu livro Narrativas do Medo, Matheus (2011) expõe a teoria elaborada pelo autor sobre os níveis de medo, onde o primeiro nível seria composto pelas angústias, melancolia e o medo do desconhecido, muito comuns para a grande parte das pessoas. Enquanto o segundo nível, "seriam reflexos dos primeiros, objetivados em elementos do cotidiano [...]. Alguns medos são objetivados em determinados momentos como se esperassem a oportunidade de emergir de um subsolo inconsciente" (MATHEUS, 2011). O medo de atos de terrorismo praticados por extremistas religiosos que é amplificado nesta produção midiática integra uma longa lista de medos aos quais precisam enfrentar os cidadãos na contemporaneidade ao redor do mundo. Matheus (2011) questiona se "os meios de comunicação acabam por despertar a sensação de falta de controle sobre a realidade, de insegurança, de angústia" (MATHEUS, 2011) ou "se a mídia não seria uma maneira de 
vivenciar o medo de modo menos assustador, controlando-o sob a forma discursiva" (MATHEUS, 2011). Impotência ou controle?

Após duas horas de programa é lícito questionar se a produção rememorou e intensificou o medo do cidadão francês novamente um ano após a tragédia. Ao apontar treze importantes e impactantes falhas ${ }^{9}$ nos serviços de proteção e apoio ao cidadão com dramatizações bem produzidas, testemunhos de sobreviventes, policiais que atuaram no momento dos ataques, funcionários e líderes de órgãos competentes do governo, socorristas e políticos, a impressão que permanece, depois dos créditos finais é a de que a França se encontra vulnerável. Vários depoimentos confirmam esse sentimento. Uma agente de informação do DGSI ${ }^{10}$, Diane ${ }^{11}$, em entrevista reconstituída para manter seu anonimato, afirma que o relatório de um interrogatório realizado com um francês que acabara de voltar da Síria, três meses antes dos atentados, expõe o plano do terrorista líder dos ataques de 13 de novembro, Abdelhamid Abaaoud. O programa simula com um ator, a fala do interrogado.

Reda Hame: ele (Abdelhamid Abaaoud) é muito perigoso. Pediu-me para escolher um alvo fácil, como um grupo de pessoas, um show, por exemplo, onde houvesse muita gente. Orientou-me que depois da ação, eu aguardasse a chegada das forças de intervenção antiterroristas e morresse em combate, junto com os reféns. ${ }^{12}$

\footnotetext{
9 O programa aponta 13 falhas cometidas na noite dos atentados: 1 - decisão de trancar ou não as pessoas no estádio de futebol quando se constata a explosão de bombas do lado externo; 2- despreparo tático da polícia para situações de múltiplos ataques; 3 - alguns terroristas que participaram dos atentados já eram conhecidos dos serviços de informação antiterrorista; 4 - militares que chegam ao local são impedidos por protocolo de usarem armas de guerra no contra-ataque aos terroristas do Bataclan que atiravam pela janela do imóvel; 5 - bombeiros e socorristas são impedidos de entrar ou sair do perímetro de segurança estabelecido na região do Bataclan atrasando o socorro às vítimas; 6 - congestionamento do centro de chamadas e pouco contingente disponível do SAMU para informação e socorro às vítimas; 7 serviço de investigação antiterrorista em choque quando constata sua incapacidade em prevenir os ataques. 8 - demora na chegada e no início da intervenção da força de elite da polícia, BRI, no Bataclan; 9 - conflitos entre as forças de elite da polícia RAID e BRI; 10 - terrorista que participou dos ataques em fuga, é barrado na fronteira com Bélgica ainda na madrugada dos crimes, mas é liberado; 11 - o centro de informações montado e bem preparado pelo Ministério do Interior para apoio às famílias das vítimas não é acessado pelos cidadãos. 12 - Informação errada na identificação das vítimas. Mãe é informada que a filha morreu e só descobre cinco dias depois, que ela estava viva. 13 - o programa levanta dúvidas sobre a atuação do RAID na intervenção no imóvel onde estava escondido o líder dos atentados, Abdelhamid Abaaoud, onde parece ter havido tiros de policiais contra policiais. Abaooud foi morto nesta ação.

10 Direção Geral de Segurança Interior

11 Nome fictício para proteção da entrevistada.

12 Tradução nossa.
} 
A revelação é chocante à medida que expõe a falta de ação preventiva, mesmo após o acesso à informação tão explícita. O mesmo impacto pode ser sentido com o depoimento de um socorrista que atuou no socorro às vítimas do atentado do Bataclan, Cyrill Bonnet, se revelando impotente frente aos protocolos de segurança:

Cyrill Bonnet: A zona não estava suficientemente protegida pelas forças de segurança para que fizéssemos a remoção das vítimas. E, se não está segura, estamos sozinhos. Por isso, não tivemos reforços não importando o número de vítimas. O mais difícil para nós que somos socorristas foi vermos pessoas feridas, chegando até nós conscientes, vivas, pedindo nossa ajuda e, minutos depois, entrando em coma, em ataque cardíaco e morrendo.

Em rua próxima à casa de shows Bataclan, segundo o off do programa, 80 feridos foram levados para dois corredores, onde um grupo pequeno de socorristas improvisava no atendimento a um grande número de vítimas com os materiais disponíveis como os cintos dos seus próprios uniformes. Mykail Guedj, um dos jornalistas produtores do programa, sentado na bancada junto ao apresentador, esclarece que, como havia dúvidas sobre se haveria ou não terroristas armados escondidos ou bombas, a polícia estabeleceu um perímetro de segurança onde ninguém podia entrar ou sair, inclusive ambulâncias e bombeiros. $\mathrm{O}$ apresentador questiona o fato, logo em seguida à explicação, "então os feridos ficaram sem socorro? "13 e a coprodutora do programa, a jornalista e diretora de documentários, Caroline Benarrosh também sentada na bancada ao lado do apresentador responde destacando ainda mais o cenário de terror: “este é um problema, já que os feridos por Kalashnikov ${ }^{14}$ têm terríveis hemorragias e, para salvar um ferido com essa arma é necessário o transporte imediato para um centro cirúrgico" ${ }^{15}$. Guedj completa Benarrosh acentuando o clima chocante. "O mais frustrante é que há 400 metros deste local havia um posto médico equipado com tudo, mas que, naquele momento, ficou inacessível" 16. Em cada fala dos apresentadores no estúdio, nos questionamentos que revelam detalhes, nos relatos dos envolvidos na segurança do país ou nos resgates das vítimas se identifica

\footnotetext{
13 Tradução nossa.

14 Outra denominação para a arma AK-47. Fuzil de calibre 7,62 x 39 mm criado em 1947, por Mikhail Kalashnikov e produzido na União Soviética pela indústria estatal IZH.

15 Tradução nossa.

16 Tradução nossa.
} 
a intenção de mostrar a falta de preparo e a "confusão" que também foi responsável pela morte de diversas pessoas. Ou seja, o Estado não pode proteger seus cidadãos que também foram vítimas de incompetência na ação. $\mathrm{O}$ apresentador reforça a necessidade de não se ignorar os riscos aos quais ficam submetidos os socorristas, o que ele denomina de "dilema". O tom dramático continua nos depoimentos de voluntários que ajudaram a reanimar feridos nos bares e restaurantes atacados e dos próprios policiais se deparando com as cenas de terror. A major Sophie $\mathrm{T}^{17}$, cujo rosto não é revelado, classificou de "carnificina" a cena presenciada por ela no bar com o maior número vítimas, o Belle Equipe, que teve 20 mortos e 17 feridos. Em sua entrevista, Sophie conta que é acionada pelo rádio quando está jantando e relata a dificuldade que teve em encontrar o endereço correto. O áudio real do rádio da policial revela que a major se encontrava pedida pelas ruas do llème arrondissement, bairro onde ocorreu a maioria dos ataques. Despreparo? Casualidade? Muitas dúvidas despejadas em sequência para a reflexão do telespectador.

Contudo, a entrevista mais detalhada e longa do programa é a de Stéphane T., cientista da computação, 50 anos, um dos reféns sobreviventes da casa de espetáculos Bataclan. Stéphane relata minuciosamente cada momento de terror que, no local, durou mais de duas horas. Ele relembra suas decisões tomadas sob pressão, como o dilema entre fugir e correr o risco de ir ao encontro de um dos terroristas ou de se esconder; o pânico da multidão; os gritos dos feridos pedindo ajuda. Stéphane detalha as reivindicações dos terroristas, seus diálogos, o estado psicológico de "excitação" frente à cada ação tática da polícia percebidos durante o cativeiro. Sua entrevista começa com a exibição de imagens reais da banda Eagles Off Death Metal $^{18}$ que se apresentava no Bataclan naquela noite e a descrição sobre sua localização exata na plateia, o balcão do segundo andar. A entrevista é interrompida na primeira frase, quando o off descreve o início da ação dos terroristas na casa de shows mostrando cenas reais da banda tocando quando os primeiros tiros são ouvidos e sentidos pelos integrantes. Fade na tela. Sob som de tiros captados pelas imagens reais gravadas por celular. Volta o off informando que, neste momento, os terroristas deram 250 tiros ininterruptos direcionados ao público. Animações em 3D

17 Nome fictício para proteção de anonimato
18 Banda americana de rock metal. 
reconstituem todas as cenas de agonia relatadas meticulosamente por Stephane, passando pela intervenção do $\mathrm{BRI}^{19}$, o suicídio dos terroristas, até a liberação de todos os reféns com vida. De acordo com Matheus (2011), a ilustração ainda que estática nas páginas do jornal, já é um recurso da estética sensacionalista, um efeito dramático utilizado em abundância e em movimento nesta produção exibida pelo canal France2. A entrevista do sobrevivente permeia a narrativa que optou por uma abordagem estritamente sensacionalista do ataque mais mortal da noite, costurando o enredo e reconstituindo a agonia ilustrada, encenada, registrada e relatada deste histórico 13 de novembro.

\title{
Considerações finais
}

Kleber Mendonça (2002) discute em seu livro, A Punição pela Audiência, a ideia da construção do espetáculo através da utilização em larga escala por programas jornalísticos de imagens de simulação cujo conteúdo são acontecimentos violentos. "A simulação como produtora de uma verdade capaz de mobilizar o telespectador" (MENDONÇA, 2002). Com a evolução tecnológica dos meios de comunicação a imagem vai se sofisticando na veiculação da informação. Novas tecnologias possibilitam recursos visuais na TV e no cinema com uma multiplicidade de possibilidades, transformando simples imagens num impressionante efeito de realidade. $\mathrm{O}$ recurso de animações em 3D e reconstituições encenadas de várias cenas referentes aos atentados são demonstrações da tentativa de se atingir um nível apontado como "status de verdade" por Mendonça (2002).

\begin{abstract}
A questão da construção da verdade jornalística não gira em torno da objetividade, mas da capacidade de uma produção de sentido específica, constituída a partir da imagem como vetor consensual que, ao produzir o efeito de realidade, constrói também a certeza da incompetência do poder público, o pânico social fruto da sensação de catástrofe iminente e o consequente desejo de vingança. (MENDONÇA, 2002, p.52).
\end{abstract}

Matheus (2011) afirma que o contato direto e diário com a iminência do caos transmitida pela mídia impregna no imaginário dos cidadãos causando insegurança e motivando a necessidade se defender em grupo. O medo individual se transforma em

\footnotetext{
19 Brigada de investigação e intervenção da polícia francesa. A sigla significa Brigade,Recherche,
} Intervention. 
medo coletivo na experiência urbana e se constitui para Matheus (2011), num criador de "vínculos memoráveis". "São indicadores empíricos da memória coletiva, por exemplo, os crimes que fundamentam os sentimentos de pertencimento e as fronteiras socioculturais. Formam-se assim, a identidade de si e do outro, o inimigo interno e o traidor" (MATHEUS, 2011).

Ao espetacularizar a tragédia, por mais espetacular que ela seja, enfatizando a origem étnica, as motivações religiosas dos terroristas e as falhas nos esquemas de segurança do país incluindo a facilidade de acesso ilegal pelas fronteiras, cenas de violência e pânico, a mídia parece disseminar ainda mais a ideia do medo coletivo e do distanciamento necessário e precavido do altero. "O outro pode ser também um grupo social concentro ao qual não pertencemos" (MATEUS, 2001). Mesmo sendo os terroristas, em sua maioria, franceses ou belgas, suas origens familiares árabes são reveladas e enfatizadas em artes gráficas exibidas na tela como fichas policiais com suas fotos, nomes, sobrenomes, idade e datas em que partiram para a Síria. Desde a vinheta de abertura até o fechamento do programa, vemos testemunhos aterrorizados, desculpas governamentais para erros cometidos, imagens chocantes, tristeza, atos de heroísmo, sentimento de impotência e terror, muito terror. As imagens de reconstituições carregadas de dramaticidade compostas por diversos elementos estéticos de suspense e ação; a construção de um enredo incluindo dezenas de imagens reais capturadas por celulares e câmeras de segurança e testemunhas; mapas da cidade identificando, como num jogo de gato e rato, a localização e percurso de terroristas e policiais intercaladas com animações em 3D, carregam não só a finalidade simbólica de rememorar detalhadamente os acontecimentos da noite de 13 de novembro, mas de chocar e questionar duramente a segurança do país. "Desde então, a ameaça mudou de rosto, forma, estilo. Seja no volante de um caminhão, na casa de policiais, dentro de uma igreja, os terroristas continuam a atacar mesmo frente a toda a estrutura de segurança montada", encerra o apresentador David Pujadas. "Ainda há muito trabalho para os homens e mulheres nas células de crise", completa.

Mesmo apoiada na máxima jornalística da disseminação da verdade e da informação, há nesta produção midiática efeitos colaterais previstos ou não: a 
disseminação da insegurança coletiva, a ideia da vida cotidiana sob risco e o fortalecimento do medo do "outro" que, sendo radical nos ataques, é personificado no cotidiano pelo imigrante árabe muçulmano, seja ele apenas o vizinho do prédio, o amigo da escola ou um trabalhador ordinário francês de descendência árabe.

\section{Referências}

BARDIN, Laurence. Análise de Conteúdo. Tradução de Luís Antero Reto. Edições 70: São Paulo, 2016.

BECK, Ulrich. Sociedade de risco: rumo a uma outra modernidade. Tradução de Sebastião Nascimento. Editora 34: São Paulo, 2010.

BAUMAN, Zygmunt. Modernidade Líquida. Tradução de Plínio Dentzien: Rio de Janeiro, Zahar, 2001.

COUVELAIRE, Louise. Les Attentats de janvier 2015 on fait plus de 200 victimes. Disponível em: $<$ http://www.lemonde.fr/societe/article/2017/01/09/le-dernier-bilan-des-attentats-de-janvier$2015 \quad 5059581$ 3224.html $>$. Acesso em 10 de janeiro de 2017.

GIDDENS, Anthony. Mundo em descontrole: o que a globalização está fazendo de nós. Tradução: Maria Luiza X. A. Borges. Rio de Janeiro: Editora Record, 2003.

MATHEUS, Letícia. C. Narrativas do medo: o jornalismo de sensações além do sensacionalismo. Rio de Janeiro: Mauad X, 2011.

MENDONÇA, Kleber. A punição pela audiência: um estudo do Linha Direta. Quartet Editora \& Comunicação Ltda.: Rio de Janeiro, 2002.

NEVES, Teresa C. Comédias de uma vida arriscada: risco e riso na crônica contemporânea brasileira. 2014. 218 f. Tese (Doutorado em Letras). Faculdade de Letras, Universidade Federal de Juiz de Fora, Juiz de Fora. 2014.

SOUZA, Fabíola. Testemunhas do terror: o ataque a Paris segundo os brasileiros. INTERCOM, XXXIX, 2016, São Paulo. Anais... Disponível em: $<$ http://portalintercom.org.br/anais/nacional2016/resumos/R11-0100-1.pdf $>$. Acesso em 05 de dezembro de 2016.

Vídeo analisado:

CELLULE DE CRISE: 13 NOVEMBRO, QUAND LA FRANCE VACILLE

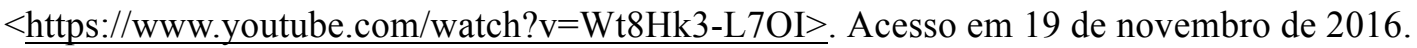

